\title{
Anesthetic Routines: The Anesthesiologist's Role in GI Recovery and Postoperative Ileus
}

\author{
John B. Leslie, ${ }^{1}$ Eugene R. Viscusi, ${ }^{2}$ Joseph V. Pergolizzi Jr., ${ }^{3}$ \\ and Sunil J. Panchal ${ }^{4}$ \\ ${ }^{1}$ Department of Anesthesiology, Mayo Clinic, 13400 East Shea Boulevard, Scottsdale, AZ 85259-5404, USA \\ ${ }^{2}$ Department of Anesthesiology, Jefferson Medical College, Thomas Jefferson University, 111 South 11th Street, PA 19107, USA \\ ${ }^{3}$ Naples Anesthesia and Pain Management Group, Department of Medicine, School of Medicine, Johns Hopkins University, \\ Baltimore, MD 21205-2196, USA \\ ${ }^{4}$ National Institute of Pain, 4911 Van Dyke Road, Lutz, FL 33558, USA
}

Correspondence should be addressed to John B. Leslie, leslie.john@mayo.edu

Received 24 June 2010; Accepted 13 November 2010

Academic Editor: Masaru Shimada

Copyright () 2011 John B. Leslie et al. This is an open access article distributed under the Creative Commons Attribution License, which permits unrestricted use, distribution, and reproduction in any medium, provided the original work is properly cited.

\begin{abstract}
All patients undergoing bowel resection experience postoperative ileus, a transient cessation of bowel motility that prevents effective transit of intestinal contents or tolerance of oral intake, to varying degrees. An anesthesiologist plays a critical role, not only in the initiation of surgical anesthesia, but also with the selection and transition to effective postoperative analgesia regimens. Attempts to reduce the duration of postoperative ileus have prompted the study of various preoperative, perioperative, and postoperative regimens to facilitate gastrointestinal recovery. These include modifiable variables such as epidural anesthesia and analgesia, opioid-sparing anesthesia and analgesia, fluid restriction, colloid versus crystalloid combinations, prokinetic drugs, and use of the new peripherally acting mu-opioid receptor (PAM-OR) antagonists. Review and appropriate adaptation of these multiple modifiable interventions by anesthesiologists and their surgical colleagues will facilitate implementation of a best-practice management routine for bowel resection procedures that will benefit the patient and the healthcare system.
\end{abstract}

\section{Introduction}

An anesthesiologist plays a critical role not only in the initiation of surgical anesthesia but also in the selection and transition to an effective maintenance of postoperative analgesia. All patients undergoing bowel resection (BR) experience postoperative ileus (POI), a transient cessation of bowel motility that prevents effective transit of intestinal contents or tolerance of oral intake, to varying degrees [1-3]. Clinically, POI is characterized by delayed passage of flatus and stool, bloating, abdominal distension, abdominal pain, nausea, and vomiting and is associated with an increase in postoperative morbidity and length of hospital stay (LOS) [4].

Although the etiology of POI is complex (Figure 1), it is primarily associated with the surgical stress response, an acute inflammatory response associated with manipulation of the bowel, and endogenous opioids secreted within the gastrointestinal (GI) tract in response to surgical trauma [37]. Opioid-based analgesia is widely used and considered the standard of care for postoperative pain management [812]. Opioids mediate analgesia by binding to mu-opioid receptors in the central nervous system [13]; however, they also bind to peripheral mu-opioid receptors in the GI tract resulting in a disruption of the migrating motor complex and propulsive motor activity associated with GI motility, inhibition of intestinal ion and fluid secretion, and an increase in the overall GI transit time, thereby exacerbating POI $[9,13]$.

Attempts to reduce the duration of POI have prompted the study of various preoperative, perioperative, and postoperative regimens to facilitate GI recovery. This review focuses on the anesthetic management routines (e.g., opioidsparing anesthesia and analgesia, epidural anesthesia and 


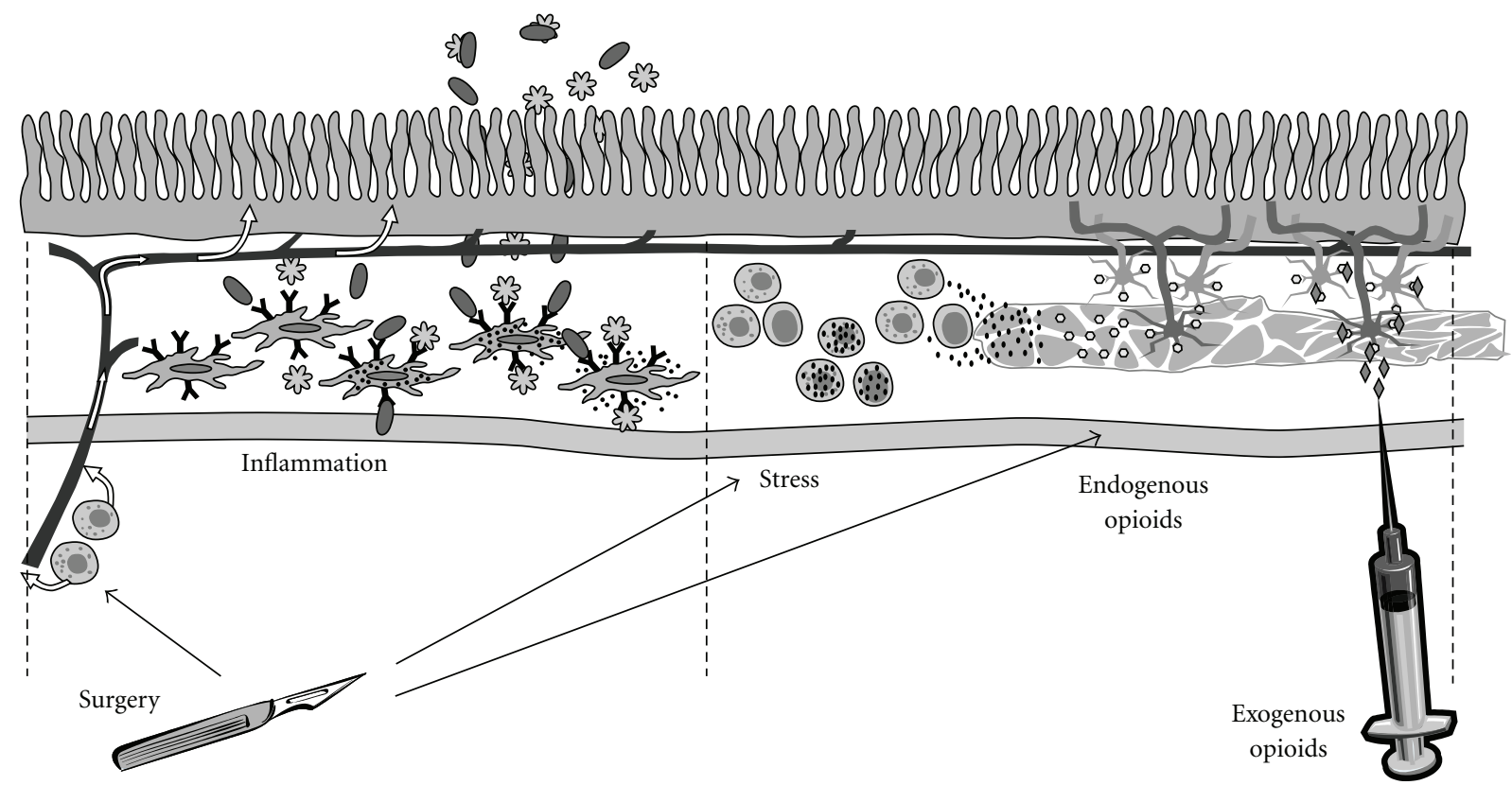

FIGURE 1: The multifactorial etiology of postoperative ileus (POI). Development of POI is multifactorial. Surgical incision and manipulation of the intestines activate inflammatory and stress responses and endogenous opioids. Mast cells release vasoactive substances diffusing into blood vessels. These substances increase mucosal permeability, allowing entrance of luminal bacteria or LPS into lymphatics or interaction with resident macrophages. Damaged tissue also activates macrophages, increasing expression of proinflammatory genes. Stress causes macrophages to release chemokines and inflammatory cytokines, which attract leukocytes to the intestinal muscularis. Large amounts of nitric oxide and prostaglandins are released, which impair smooth muscle contraction. Endogenous opioids are released, which disrupt GI transit and motility. Exogenous opioid analgesia also disrupts GI motility.

analgesia, and use of peripherally acting mu-opioid receptor (PAM-OR) antagonists) that may result in reduced time to gastrointestinal recovery and hospital length of stay. Application of these interventions by anesthesiologists and best practice management routines across the institution may benefit the patient and the healthcare system.

\section{Discussion}

2.1. Can We Modify the Anesthetic Routines to Minimize POI?. The anesthesiologist can contribute to the design and implementation of a best practices routine that defines optimal management routines aimed at accelerating return of GI function and minimization of patient discomfort and costs. One of the first key management decisions the anesthesiologist can help guide is the prevention and management of pain. Because opioid use is clearly linked to adverse GI effects, there is a general consensus that epidural analgesia and other opioid-sparing techniques will improve postoperative GI outcomes. The two most common techniques currently used for management of postoperative pain are epidural analgesia and intravenous patient-controlled analgesia (IV-PCA). Epidural analgesia is generally initiated in the perioperative period and continued throughout the postoperative period for up to 3 postoperative days [8]. Gastrointestinal function was reported in several studies to return 48 to 72 hours earlier in patients receiving thoracic epidural anesthesia and postoperative epidural analgesia compared with patients receiving IV-PCA [10-12]. Thoracic epidurals with local anesthetic (i.e., bupivacaine) significantly reduced duration of POI compared with systemic opioid therapy in patients undergoing abdominal surgery in randomized trials with comparable pain management $(P<.05)$ [14-18]. Epidural bupivacaine compared with epidural opioids alone or epidural bupivacaine and morphine combinations significantly reduced the incidence of postoperative nausea and vomiting $(P<.01)[19]$, reduced time to first bowel movement [20], and significantly reduced time to GI recovery $(P<.005)[17]$ in multiple double-blind studies [18]. Alternatively, when a fast-track postoperative care pathway was used in a recent, randomized controlled trial $(N=56)$ using either thoracic epidural analgesia with bupivacaine and fentanyl for 2 days versus IV-PCA that included opioid-sparing ketorolac, comparable outcomes were obtained for length of stay, pain scores, quality of life, complications, and hospital costs [21].

2.1.1. Opioid-Sparing Analgesia. The strategy to ameliorate negative effects of opioids on the GI tract in the postoperative period (e.g., POI and postoperative nausea and vomiting (PONV)) is often best managed by simply reducing patient exposure to opioids. In a metaanalysis of 52 randomized placebo-controlled trials comparing nonsteroidal antiinflammatory drugs (NSAIDs), cyclooxygenase-2 (COX-2) inhibitors, and acetaminophen administered in conjunction with morphine after surgery, morphine consumption was 
reduced $15 \%$ to $55 \%$ compared with morphine alone. Moreover, NSAIDs administered in conjunction with morphine reduced the incidence of nausea and vomiting from $28.8 \%$ to $22.0 \%$ compared with morphine alone [22]. In a randomized, double-blind, placebo-controlled study of total hip arthroplasty, addition of COX-2 inhibitors reduced morphine consumption by $40.5 \%$ [23]. In 2 prospective, randomized, double-blind studies in patients undergoing colorectal surgery, the addition of ketorolac to morphine IV-PCA had an opioid-sparing effect (patients administered ketorolac received $18.3 \%$ to $29 \%$ less morphine than patients with comparable pain scores who self-administered morphine alone via PCA) [24, 25]. However, the effect of ketorolac on time to first bowel movement was not always consistent. In 1 study, time to first bowel movement was significantly improved in patients who received ketorolac plus morphine compared with morphine alone, (ketorolac plus morphine, 1.8 days; morphine, 2.4 days; $P<.001$ ), and patients who received morphine alone had a 5.25 greater risk of developing POI [25]. However, in the second study the addition of ketorolac did not improve time to first bowel movement (ketorolac and morphine, 1.5 days; morphine, 1.7 days; $P<.05$ ) or time to first ambulation (ketorolac and morphine, 2.2 days; morphine, 2.8 days; $P<.05$ ) [24]. Additional larger prospective trials are required to determine the benefits of ketorolac on POI. Continuous infusion of lidocaine to augment postoperative analgesia also can reduce the need for opioids, and a metaanalysis review of 8 published trials provides demonstrated benefits in reducing the duration of POI [26].

Gabapentin, a calcium channel modulator, $(1,200 \mathrm{mg}$ by mouth 1 hour before surgery) reduced opioid consumption after abdominal surgery compared with placebo in 2 randomized, double-blind trials $[27,28]$. Morphine and tramadol consumption after abdominal hysterectomy were reduced in randomized, double-blind, placebo-controlled studies after administration of gabapentin compared with placebo (morphine was reduced by $20 \mathrm{mg} ; P<.001$; tramadol was reduced by $149 \mathrm{mg}$ over 24 hours) $[27,28]$. Administration of oral gabapentin preoperatively and 24 hours postoperatively reduced morphine consumption by $32 \%$ compared with placebo without substantially affecting pain scores in patients undergoing hysterectomy [27]. Fentanyl consumption, as a rescue analgesic, was also reduced in patients undergoing laparoscopic cholecystectomy who received gabapentin in a randomized, doubleblind study [29]. However, the effect of this and other opioidsparing techniques (e.g., off-label use of the alpha-2 agonist dexmedetomidine as a single loading dose or a continuous infusion perioperatively) on POI has yet to be specifically measured. These and other compounds may exert more direct effects on duration of POI, beyond the opioid-sparing benefit, when administered as part of a multimodal analgesic approach.

Tapentadol, a centrally acting synthetic opioid analgesic, has been approved for use in patients with moderate to severe acute pain [30]. Although the exact mechanism of action is not known, the analgesic effect of tapentadol may be attributed to mu-opioid agonist activity and inhibition of norepinephrine reuptake [30]. The affinity of tapentadol for mu-opioid receptors is 18-times lower than that for morphine; however, tapentadol is only 2 to 3 times less potent in producing analgesia in animal models [30-32]. In a randomized, double-blind, placebo- and active-controlled study, tapentadol $50 \mathrm{mg}$ demonstrated similar pain relief after orthopedic surgery and produced significantly less nausea and/or vomiting compared with oxycodone IR $10 \mathrm{mg}$ [33]. Tapentadol has not been specifically studied for reducing the duration of POI; however, its opioid-sparing analgesic effect could potentially provide benefit in the context of a multimodal pathway.

2.1.2. Epidural Anesthesia. All anesthetics used for induction or maintenance of general anesthesia may depress GI motility $[8,34]$. When choosing an anesthetic regimen, the decision to include epidural anesthesia, insertion location of the epidural, selection of inhaled anesthesia agents, use of neuromuscular reversal agents, the extent of the effects of the regimens on the GI tract, and GI recovery should be considered $[8,35]$. Differences in these multiple anesthetic variables in previous studies also help to explain the conflicting results of the effects of anesthesia on the GI tract and may affect the duration of POI demonstrated across studies $[8,35]$.

Location of epidural placement, selection of the epidural infusion mixture, and timing of the first epidural bolus dose are important factors for the risk of developing POI. In abdominal surgeries such as colon resection, the positive effect of an epidural local anesthetic may only be evident when administered in the thoracic region, as it is related to segmental visceral afferent/efferent blockade [8]. In general, thoracic epidural analgesia is associated with improved GI recovery compared with lumbar or systemic analgesia [12]. Numerous studies using lumbar or lowthoracic epidural administration of local anesthetics have failed to demonstrate the positive effects of epidural analgesia on the reduction of the duration of POI $[16,17,36-38]$. Low thoracic (T9 to T12) epidural blockade or dosing of the epidural only after the surgical procedure is completed may not permit sufficient dermatomal blockade of noxious stimuli to eliminate development of a prolonged inhibition of GI motility and facilitate a posttraumatic rapid return to normal function [8].

2.1.3. Perioperative Fluid Administration. Perioperative fluid is administered to meet hourly fluid requirements and to replace fluids lost during surgery [39]. However, excess perioperative fluid administration may lead to edema of the GI tract, resulting in prolonged ileus [40]. Postoperative ileus was reduced in a small, randomized study $(N=20)$ in patients undergoing colonic surgery who were placed under fluid restriction ( $\leq 2 \mathrm{~L}$ water and $77 \mathrm{mmol}$ sodium per day) during surgery compared with patients who received more liberal fluid management ( $\geq 3 \mathrm{~L}$ water and $154 \mathrm{mmol}$ sodium per day) [41]. In this study, positive salt and water balance sufficient to cause a $3-\mathrm{kg}$ weight gain delayed return of GI function (median passage of flatus 1 day later and laxation 2.5 days later than patients who received restricted fluids) 
and hospital discharge ( 9 postoperative days for patients who received liberal fluids versus 6 postoperative days for patients who received restricted fluids). Furthermore, in a larger randomized study $(N=152)$, patients who received liberal fluids had a significantly longer time to first passage of flatus (Lactated Ringer's $12 \mathrm{~mL} / \mathrm{kg} / \mathrm{hr}, 4$ days; Lactated Ringer's $4 \mathrm{~mL} / \mathrm{kg} / \mathrm{hr}, 3$ days; $P<.001$ ) or bowel movement (Lactated Ringer's $12 \mathrm{~mL} / \mathrm{kg} / \mathrm{hr}, 6$ days; Lactated Ringer's $4 \mathrm{~mL} / \mathrm{kg} / \mathrm{hr}, 4$ days; $P<.001$ ) and were discharged from the hospital 1 day later (Lactated Ringer's $12 \mathrm{~mL} / \mathrm{kg} / \mathrm{hr}, 9$ days; Lactated Ringer's $4 \mathrm{~mL} / \mathrm{kg} / \mathrm{hr}, 8$ days; $P=.01$ ) than patients who received restrictive fluids [42]. There were significantly more perioperative complications in patients who received liberal fluids $(n=23)$ compared with patients who received restricted fluids ( $n=13 ; P<.05)$; however, there were more episodes of hypotension in patients who received restricted fluids (36 episodes in 20 patients) compared with patients who received liberal fluids ( 1 episode in 1 patient) [42].

The use of crystalloid infusions rather than colloids may also predispose patients to excessive intestinal edema [43]. In a small, randomized study $(N=18)$, intestinal edema was demonstrated in patients who received crystalloids during surgery and not in patients who primarily received colloids during surgery [43]. However, while use of fluid restriction rather than liberal fluid administration to replace fluids lost during surgery is recommended, this technique has not entered routine clinical use [39]. Further investigations of fluid restrictions, as well as crystalloids and colloid combinations, are necessary to reach a final consensus on optimal fluid resuscitation and maintenance routines.

2.1.4. Pharmacologic Treatments. Activation of the inducible form of nitric oxide synthase (iNOS) directly modulates intestinal dysmotility after bowel manipulation and is involved in the initiation of intestinal inflammation [5]; therefore, inhibition of iNOS may play a role in reducing duration of POI. In a recent preclinical study, S-methylisothiourea sulfate, an iNOS inhibitor, improved small intestine motility in a canine postoperative model after surgical intestinal manipulation [44]. Further studies are warranted.

Prokinetic agents accelerate gastric emptying or colonic transit and may, therefore, reduce the duration of POI [45]. There are many subclasses of prokinetic agents that theoretically address the multifactorial etiology of POI, including acetylcholinesterase inhibitors, somatostatin analogues, and receptor agonists and antagonists. However, despite promising preclinical data, overall, prokinetic agents have generally failed to demonstrate clinical efficacy in the management of POI, and additional agents are being investigated [46].

Phase I studies have demonstrated that neostigmine, an acetylcholinesterase inhibitor, increases postoperative colonic motility and tone in healthy volunteers and patients undergoing colorectal surgery [47]. Preclinical studies on the somatostatin analogue octreotide demonstrated increased intestinal motility in dogs after small-bowel autotransplantation and amelioration of POI $[48,49]$. Receptor-specific compounds (e.g., serotonin and motilin receptor agonists, dopamine and cholecystokinin-1 [CCK-1] receptor antagonists) have also demonstrated some motility-promoting activity $[45,50,51]$. Although multiple serotoninergic agonists (i.e., cisapride, tegaserod, and renzapride) have demonstrated efficacy in promoting GI motility, their beneficial effects are limited because of serious adverse side effects [5254].

Although the antibiotic erythromycin, a motilin receptor agonist, stimulated gastric motility in healthy volunteers $[45,55-57]$, erythromycin failed to demonstrate any benefit in the management of POI after abdominal surgery [58], and erythromycin did not reduce the rate of nausea, vomiting, or nasogastric tube (NGT) placement in patients after colorectal surgery in a recent randomized double-blind study [59]. Numerous studies have failed to demonstrate any benefit of metoclopramide in the management of POI [6062]. Despite promising preclinical data, overall, prokinetic agents generally fail to demonstrate clinical efficacy in the management of POI, and additional agents are needed [46].

2.2. Are the Opioids the Real Culprits in POI? All patients undergoing major abdominal surgery are at risk for POI [13]. Although the etiology of POI is complex (Figure 1), it is primarily associated with surgical trauma and manipulation of the bowel, inhibitory neural reflexes, secretion of endogenous opioids within the GI tract, and exogenous opioid-based analgesia [4-6, 9, 63-66]. Surgical trauma and manipulation activate inhibitory sympathetic neural reflexes in the GI tract and induce the release of catecholamines, inflammatory mediators, and endogenous opioids. Increased levels of endogenous opioids during surgical trauma to the bowel contribute to impaired GI motility, GI secretions, and POI $[5,13,67]$.

Opioid-based analgesia is widely used and considered the standard of care for postoperative pain management [9, 13,68 ]. Opioids mediate analgesia by binding to mu-opioid receptors in the central nervous system [13]; however, they also bind to peripheral mu-opioid receptors in the GI tract, resulting in a disruption of the migrating motor complex and propulsive motor activity associated with GI motility, inhibition of intestinal ion and fluid secretion, and an increase in the overall GI transit time, thereby exacerbating POI $[9,13]$.

\subsection{Do the PAM-ORs Really Reduce POI? Peripherally acting} mu-opioid receptor antagonists, such as the FDA-approved alvimopan and investigational methylnaltrexone, do not appear to reverse central opioid action and may give anesthesiologists and surgeons the option of using preemptive opioid analgesics without substantial opioid-associated GI adverse effect $[9,69-79]$. Methylnaltrexone has been studied predominantly in patients with opioid-induced bowel dysfunction. More recent clinical studies have reported laxation and reduced oral-cecal transit times after multiple doses of methylnaltrexone in patients with opioid-induced constipation because of methadone maintenance therapy $[71,80]$. Methylnaltrexone also reversed opioid-induced 
TABLE 1: Components of a multimodal management pathway for patients undergoing bowel resection.

Pathway component
Preoperative patient education and optimization of medical ill
and nutritional status
(i) Evaluation and discussion of operative anesthetic plan and
perioperative pain management program

(ii) Assessment of pain tolerance, history of current and past opiate use and tolerance

Epidural anesthesia and postoperative analgesia

\section{IV-PCA}

Opioid-sparing adjuncts such as NSAIDs, dexmedetomidine, lidocaine infusion, and gabapentin

Patients with planned IV-PCA or opioid tolerance problems evaluated for preoperative initiation of PAM-OR antagonists

Preoperative antiemetics and gastric antacids/emptying

Preoperative warming blankets and anxiolysis as needed

Laparoscopic surgery

Limited NGT use postoperatively

Minimize intraoperative fluids and consider colloid administration

Early oral/enteral/sham (gum chewing) feeding initiated POD1

Minimize postoperative opioids

Advancing of diet as tolerated

Postoperative laxatives

Early ambulation

Discharge planning communication
Benefit-issues

Reduce preoperative anxiety, minimize perioperative risks, and enhance postoperative recovery $[103,104]$

Assurance of adequate pain control and selection of appropriate pain management techniques will help with process of controlling sympathetic reflexes, afferent pain and stress-released neuropeptides, and multiple factors contributing to motility inhibition [105]

Epidural should be thoracic and utilize local anesthetic infusion initiated early during the surgical procedure to minimize any responsiveness [50]

Insertion and management of epidural must be coordinated with plans for perioperative DVT prophylaxis (e.g., subQ heparin) [11]

Patients with history of chronic opioid use will likely benefit from use of adjuncts or local anesthetic epidural in combination with IV-PCA to avoid acute withdrawal symptoms [108]

Patients with history of opioid intolerance (e.g., PONV, constipation, POI) may benefit from opioid-sparing technique(s) and the addition of PAM-OR antagonists [27, 102, 111, 115]

PAM-OR antagonists will reverse adverse effects of opioids on GI function without compromising analgesia;

PAM-OR antagonists contraindicated in patients on chronic opioids [83]

Optimize option of early NGT removal at end of procedure; consider $5 \mathrm{HT}_{3}$, metoclopramide, and dexamethasone [110, 112]

Reduce intraoperative hypothermia, and reduce preinduction stresses [35]

Reduced manipulation and trauma of the bowel leads to less sympathetic activation and inflammation; reduce postoperative pain and associated opioid use [113]

Utilize intraoperatively but remove at end of procedure as discussed for each case with surgeon; allows resumption of early oral intake [109]

Reduce bowel edema and accelerate GI recovery [43]

Stimulation of GI hormones [95]

Use of nonopioid analgesics and transition from IV-PCA if used to oral agents when possible with IV opioids used only for breakthrough severe pain [89]

If clear liquids tolerated on POD1 then advance to soft diet POD2 [86]

Help to induce bowel movement [114]

Helps to prevent postoperative complications such as thrombosis, atelectasis, and pneumonia [106]

Will need to work toward multiple components to have patient achieve toleration of adequate oral intake without PONV, adequate pain control, evidence of lower GI activity (stool or gas per surgeon routine), independent ambulation, and adequate support available at home [107]

Abbreviations: DVT: deep vein thrombosis; GI: gastrointestinal; IV-PCA: intravenous patient-controlled analgesia; NGT: nasogastric tube; NSAIDS: nonsteroidal anti-inflammatory drugs; PAM-OR: peripherally acting mu-opioid receptor; POD: postoperative day; POI: postoperative ileus; PONV: postoperative nausea and vomiting; subQ: subcutaneously; TID: three times daily. 
constipation in patients undergoing chronic opioid treatment for oncologic pain [81]. Intravenous methylnaltrexone $(0.3 \mathrm{mg} / \mathrm{kg})$ accelerated GI recovery (methylnaltrexone, 124 hours; placebo, 151 hours; $P=.06$ ) and discharge time (methylnaltrexone, 140 hours; placebo, 165 hours; $P=.09$ ) in a recent phase II POI trial in patients undergoing segmental colectomy via laparotomy [73]. Opioid consumption was comparable for methylnaltrexone and placebo groups [73]. According to a 2008 Wyeth news press release, a multicenter phase III trial to investigate the efficacy of methylnaltrexone ( 12 to $24 \mathrm{mg} / \mathrm{kg}$ intravenous every 6 hours) in patients undergoing bowel resection via laparotomy did not meet the primary endpoint of decreased time to GI recovery after bowel resection, or its secondary endpoints, including time to discharge eligibility [82].

Alvimopan is an oral PAM-OR antagonist with low bioavailability (6\%) that was approved by the FDA in 2008 for the management of POI [83]. Alvimopan accelerated time to GI recovery and time to hospital discharge order written compared with placebo in 4 North American phase III trials of POI in patients undergoing bowel resection via laparotomy receiving opioid-based IV-PCA [72, 74, 77-79]. In a fifth phase III trial that was conducted in Europe, the benefits of alvimopan were seen in a post hoc subgroup analysis of patients who received opioid-based IV-PCA for at least the first 48 hours after surgery [76]. Consistent with the role of opioids in the pathoetiology of POI, acceleration of GI recovery for alvimopan versus placebo was not statistically significant in this trial in patients who did not receive opioidbased IV-PCA [76].

Retrospective analyses of the phase III alvimopan trials have demonstrated additional benefits to the patient and the healthcare system. Patients receiving alvimopan $12 \mathrm{mg}$ were less likely to experience POI-related morbidity than patients receiving placebo (odds ratio $=0.44, P \leq .001$ ) [84]. Furthermore, alvimopan patients were significantly less likely to require postoperative NGT insertion and had significantly fewer episodes of prolonged hospital stays or readmission to the hospital for POI symptoms $(P \leq .001)$. These reductions translate into a benefit not only to the patient but to the healthcare system as well. In a recent post hoc economic analysis of the phase III alvimopan trials the mean estimated hospital cost was $\$ 879-\$ 977$ less for patients who received alvimopan compared with placebo [85].

\subsection{What Would a Best Practices Plan Look Like? Multimodal} pathways to accelerate GI recovery and reduce the postoperative length of stay generally include early planned discharge, encouragement of early mobilization, early oral nutrition, and no routine NGT use postoperatively [86, 87]. Patients undergoing these "fast-track" postoperative management protocols consistently have a shorter hospital length of stay than patients receiving traditional care (e.g., NGT in place until bowel sounds return or the passage of flatus) [88-91]. Gum chewing, a type of sham feeding, reduced the time to first flatus and first bowel movement after laparoscopic colectomy in several small, randomized, prospective studies [92-94] and 2 metaanalyses [95].
However, results have not been consistent [96] and a wellcontrolled, rigorously designed trial is needed to further clarify the effect of gum chewing on GI recovery. Laxatives, as part of a multimodal rehabilitation regimen, were also associated with early GI recovery and hospital discharge in prospective studies [97-99]. However, few randomized controlled studies of laxatives alone (i.e., not as part of a multimodal regimen) have been conducted, and laxatives are generally not used for the management of POI after major abdominal surgery such as bowel resection [50, 100].

Administration of pharmacologic agents initiated in the perioperative period and continued through the postoperative period (e.g., epidural analgesia, PAM-OR antagonists, NSAIDS, and gabapentin) may contribute to faster GI recovery in the postoperative period $[17,29,101]$.

\subsection{How Can We Get Our Institution on Track with the Best Practice Routines for BR and POI Prevention?}

Several key components are important elements to be considered and included in an anesthesia and surgery line of service for BR (Table 1) $[11,27,35,43,50,83,86,89,95$, 102-115]. These suggestions have been shown to contribute to earlier return of GI function either as independent or component variables in similar multimodal management pathways. These factors should be considered for all patients.

\section{Conclusions}

Postoperative GI dysmotility is the primary determinate of length of hospital stay after abdominal surgery $[116,117]$. In the absence of multimodal treatment programs, mean hospital stay after colorectal surgery may be as long as 10 days [118-120]. A study of patients undergoing abdominal surgery revealed that the type and severity of the side effects of pain medications administered were more important to patients than postoperative pain control, highlighting the effect of POI on patient satisfaction [121]. Management of POI and earlier return of GI function may result in improved patient satisfaction and decreased length of hospital stay.

Multimodal techniques reduce the incidence and duration of POI. However, these multimodal techniques require the cooperation of the entire surgical team and collective knowledge of pathways, protocols, and pharmacologic agents with potential to manage POI. It is essential that anesthesiologists play a critical role in the surgical team for providing optimal preoperative, perioperative, and postoperative care. Furthermore, through preoperative discussions and patient assessment, it may be possible to enroll a patient in an individualized multifaceted approach for optimal recovery. It is vital that patients receive high-quality pain relief with minimal impairment of GI function, and that all patients are managed effectively to ensure a rapid return to their normal lifestyle.

\section{Conflict of Interests}

J. B. Leslie received clinical research funding from Adolor, Wyeth Pharmaceuticals, and Progenics, and honoraria for 
presentation at CME-sponsored events or meetings funded by grants from GlaxoSmithKline and Adolor or to those organizations. E. R. Viscusi is a consultant for Adolor, and his institution has received grant support from Adolor and Progenics. He is also a speaker for Adolor, GlaxoSmithKline, and Wyeth. J. V. Pergolizzi is a consultant for Adolor, GlaxoSmithKline, and Grünenthal. S. J. Panchal is a speaker for Adolor and GlaxoSmithKline.

\section{Acknowledgments}

Funding for medical editorial assistance was provided by Adolor Corporation, Exton, PA, and GlaxoSmithKline, Philadelphia, PA. The authors would like to thank Bret A. Wing, Ph.D., and Kerry O. Grimberg, Ph.D., ProEd Communications, Inc., Beachwood, OH, USA, for their medical editorial assistance with this paper.

\section{References}

[1] C. P. Delaney, "Clinical perspective on postoperative ileus and the effect of opiates," Neurogastroenterology and Motility, vol. 16, no. 2, pp. 61-66, 2004.

[2] E. H. Livingston and E. P. Passaro, "Postoperative ileus," Digestive Diseases and Sciences, vol. 35, no. 1, pp. 121-132, 1990.

[3] G. E. Boeckxstaens and W. J. de Jonge, "Neuroimmune mechanisms in postoperative ileus," Gut, vol. 58, no. 9, pp. 1300-1311, 2009.

[4] H. Kehlet and K. Holte, "Review of postoperative ileus," American Journal of Surgery, vol. 182, no. 5, pp. 3S-10S, 2001.

[5] J. C. Kalff, W. H. Schraut, R. L. Simmons, and A. J. Bauer, "Surgical manipulation of the gut elicits an intestinal muscularis inflammatory response resulting in postsurgical ileus," Annals of Surgery, vol. 228, no. 5, pp. 652-663, 1998.

[6] J. B. Leslie, "Alvimopan for the management of postoperative ileus," Annals of Pharmacotherapy, vol. 39, no. 9, pp. 1502 1510, 2005.

[7] O. Lundgren, "Sympathetic input into the enteric nervous system," Gut, vol. 47, no. 4, pp. iv33-iv35, 2000.

[8] K. Holte and H. Kehlet, "Postoperative ileus: a preventable event," British Journal of Surgery, vol. 87, no. 11, pp. 14801493, 2000.

[9] A. Kurz and D. I. Sessler, "Opioid-induced bowel dysfunction: pathophysiology and potential new therapies," Drugs, vol. 63, no. 7, pp. 649-671, 2003.

[10] S. Liu, R. L. Carpenter, and J. M. Neal, "Epidural anesthesia and analgesia: their role in postoperative outcome," Anesthesiology, vol. 82, no. 6, pp. 1474-1506, 1995.

[11] R. J. Moraca, D. G. Sheldon, and R. C. Thirlby, "The role of epidural anesthesia and analgesia in surgical practice," Annals of Surgery, vol. 238, no. 5, pp. 663-673, 2003.

[12] R. A. Steinbrook, "Epidural anesthesia and gastrointestinal motility," Anesthesia and Analgesia, vol. 86, no. 4, pp. 837844, 1998.

[13] P. Holzer, "Opioids and opioid receptors in the enteric nervous system: from a problem in opioid analgesia to a possible new prokinetic therapy in humans," Neuroscience Letters, vol. 361, no. 1-3, pp. 192-195, 2004.

[14] B. Scheinin, R. Asantila, and R. Orko, "The effect of bupivacaine and morphine on pain and bowel function after colonic surgery," Acta Anaesthesiologica Scandinavica, vol. 31, no. 2, pp. 161-164, 1987.

[15] H. Ahn, A. Bronge, K. Johansson, H. Ygge, and J. Lindhagen, "Effect of continuous postoperative epidural analgesia on intestinal motility," British Journal of Surgery, vol. 75, no. 12, pp. 1176-1178, 1988.

[16] T. Thoren, A. Sundberg, M. Wattwil, J. E. Garvill, and U. Jurgensen, "Effects of epidural bupivacaine and epidural morphine on bowel function and pain after hysterectomy," Acta Anaesthesiologica Scandinavica, vol. 33, no. 2, pp. 181$185,1989$.

[17] S. S. Liu, R. L. Carpenter, D. C. Mackey et al., "Effects of perioperative analgesic technique on rate of recovery after colon surgery," Anesthesiology, vol. 83, no. 4, pp. 757-765, 1995.

[18] K. Holte and H. Kehlet, "Epidural anaesthesia and analgesia-effects on surgical stress responses and implications for postoperative nutrition," Clinical Nutrition, vol. 21, no. 3, pp. 199-206, 2002.

[19] R. Asantila, P. Eklund, and P. H. Rosenberg, "Continuous epidural infusion of bupivacaine and morphine for postoperative analgesia after hysterectomy," Acta Anaesthesiologica Scandinavica, vol. 35, no. 6, pp. 513-517, 1991.

[20] H. Jørgensen, J. S. Fomsgaard, J. Dirks, J. Wetterslev, B. Andreasson, and J. B. Dahl, "Effect of epidural bupivacaine vs combined epidural bupivacaine and morphine on gastrointestinal function and pain after major gynaecological surgery," British Journal of Anaesthesia, vol. 87, no. 5, pp. 727732, 2001.

[21] M. Zutshi, C. P. Delaney, A. J. Senagore et al., "Randomized controlled trial comparing the controlled rehabilitation with early ambulation and diet pathway versus the controlled rehabilitation with early ambulation and diet with preemptive epidural anesthesia/analgesia after laparotomy and intestinal resection," American Journal of Surgery, vol. 189, no. 3, pp. 268-272, 2005.

[22] N. Elia, C. Lysakowski, and M. R. Tramèr, "Does multimodal analgesia with acetaminophen, nonsteroidal antiinflammatory drugs, or selective cyclooxygenase- 2 inhibitors and patient-controlled analgesia morphine offer advantages over morphine alone? Meta-analyses of randomized trials," Anesthesiology, vol. 103, no. 6, pp. 1296-1304, 2005.

[23] T. P. Malan, G. Marsh, S. I. Hakki, E. Grossman, L. Traylor, and R. C. Hubbard, "Parecoxib sodium, a parenteral cyclooxygenase 2 selective inhibitor, improves morphine analgesia and is opioid-sparing following total hip arthroplasty," Anesthesiology, vol. 98, no. 4, pp. 950-956, 2003.

[24] J. Y. Chen, G. J. Wu, M. S. Mok et al., "Effect of adding ketorolac to intravenous morphine patient-controlled analgesia on bowel function in colorectal surgery patients-a prospective, randomized, double-blind study," Acta Anaesthesiologica Scandinavica, vol. 49, no. 4, pp. 546-551, 2005.

[25] J. Y. Chen, T. L. Ko, Y. R. Wen et al., "Opioid-sparing effects of ketorolac and its correlation with the recovery of postoperative bowel function in colorectal surgery patients: a prospective randomized double-blinded study," Clinical Journal of Pain, vol. 25, no. 6, pp. 485-489, 2009.

[26] E. Marret, M. Rolin, M. Beaussier, and F. Bonnet, "Metaanalysis of intravenous lidocaine and postoperative recovery after abdominal surgery," British Journal of Surgery, vol. 95, no. 11, pp. 1331-1338, 2008.

[27] G. Dierking, T. H. Duedahl, M. L. Rasmussen et al., "Effects of gabapentin on postoperative morphine consumption and 
pain after abdominal hysterectomy: a randomized, doubleblind trial," Acta Anaesthesiologica Scandinavica, vol. 48, no. 3, pp. 322-327, 2004.

[28] A. Turan, B. Karamanlioğlu, D. Memiş, P. Usar, Z. Pamukçu, and M. Türe, "The analgesic effects of gabapentin after total abdominal hysterectomy," Anesthesia and Analgesia, vol. 98, no. 5, pp. 1370-1373, 2004.

[29] C. K. Pandey, S. Priye, S. Singh, U. Singh, R. B. Singh, and P. K. Singh, "Preemptive use of gabapentin significantly decreases postoperative pain and rescue analgesic requirements in laparoscopic cholecystectomy," Canadian Journal of Anesthesia, vol. 51, no. 4, pp. 358-363, 2004.

[30] Nucynta ${ }^{\circledR}$ (Tapentadol) Prescribing Information, Pricara, Division of Ortho-McNeil-Janssen Pharmaceuticals, Inc., Raritan, NJ, USA, 2010.

[31] T. M. Tzschentke, T. Christoph, B. Kögel et al., “(-)-(1R,2R)3-(3-dimethylamino-1-ethyl-2-methyl-propyl)-phenol hydrochloride (Tapentadol $\mathrm{HCl}$ ): a novel $\mu$-opioid receptor agonist/norepinephrine reuptake inhibitor with broadspectrum analgesic properties," Journal of Pharmacology and Experimental Therapeutics, vol. 323, no. 1, pp. 265-276, 2007.

[32] T. M. Tzschentke, J. De Vry, R. Terlinden et al., “Tapentadol hydrochloride: analgesic mu-opioid receptor agonist noradrenaline reuptake inhibitor," Drugs of the Future, vol. 31, no. 12, pp. 1053-1061, 2006.

[33] S. Daniels, E. Casson, J. U. Stegmann et al., "A randomized, double-blind, placebo-controlled phase 3 study of the relative efficacy and tolerability of tapentadol IR and oxycodone IR for acute pain," Current Medical Research and Opinion, vol. 25, no. 6, pp. 1551-1561, 2009.

[34] A. J. Ogilvy and G. Smith, "The gastrointestinal tract after anaesthesia," European Journal of Anaesthesiology, Supplement, vol. 12, no. 10, pp. 35-42, 1995.

[35] H. Kehlet and J. B. Dahl, "Anaesthesia, surgery, and challenges in postoperative recovery," The Lancet, vol. 362, no. 9399, pp. 1921-1928, 2003.

[36] G. Wallin, J. Cassuto, and S. Hogstrom, "Failure of epidural anesthesia to prevent postoperative paralytic ileus," Anesthesiology, vol. 65, no. 3, pp. 292-297, 1986.

[37] J. Neudecker, W. Schwenk, T. Junghans, S. Pietsch, B. Böhm, and J. M. Müller, "Randomized controlled trial to examine the influence of thoracic epidural analgesia on postoperative ileus after laparoscopic sigmoid resection," British Journal of Surgery, vol. 86, no. 10, pp. 1292-1295, 1999.

[38] H. Bisgaard, H. Gronborg, N. Mygind, R. Dahl, N. Lindqvist, and P. Venge, "Allergen-induced increase of eosinophil cationic protein in nasal lavage fluid: effect of the glucocorticoid budesonide," Journal of Allergy and Clinical Immunology, vol. 85, no. 5, pp. 891-895, 1990.

[39] B. Brandstrup, "Fluid therapy for the surgical patient," Best Practice and Research: Clinical Anaesthesiology, vol. 20, no. 2, pp. 265-283, 2006.

[40] K. Holte, N. E. Sharrock, and H. Kehlet, "Pathophysiology and clinical implications of perioperative fluid excess," British Journal of Anaesthesia, vol. 89, no. 4, pp. 622-632, 2002.

[41] D. N. Lobo, K. A. Bostock, K. R. Neal, A. C. Perkins, B. J. Rowlands, and S. P. Allison, "Effect of salt and water balance on recovery of gastrointestinal function after elective colonic resection: a randomised controlled trial," The Lancet, vol. 359, no. 9320, pp. 1812-1818, 2002.

[42] V. Nisanevich, I. Felsenstein, G. Almogy, C. Weissman, S. Einav, and I. Matot, "Effect of intraoperative fluid management on outcome after intraabdominal surgery," Anesthesiology, vol. 103, no. 1, pp. 25-32, 2005.

[43] T. Prien, N. Backhaus, F. Pelster, W. Pircher, H. Bunte, and P. Lawin, "Effect of intraoperative fluid administration and colloid osmotic pressure on the formation of intestinal edema during gastrointestinal surgery," Journal of Clinical Anesthesia, vol. 2, no. 5, pp. 317-323, 1990.

[44] S. Uenoyama, T. Kobayashi, Y. Takeuchi, K. Yamashita, Y. Koide, and T. Kazui, "Improvement of intestinal motility using S-methylisothiourea in postoperative ileus," American Journal of Surgery, vol. 187, no. 1, pp. 93-97, 2004.

[45] J. J. Gallican and S. Vanner, "Basic and clinical pharmacology of new motility promoting agents," Neurogastroenterology and Motility, vol. 17, no. 5, pp. 643-653, 2005.

[46] T. J. Bungard and P. B. Kale-Pradhan, "Prokinetic agents for the treatment of postoperative ileus in adults: a review of the literature," Pharmacotherapy, vol. 19, no. 4, pp. 416-423, 1999.

[47] M. E. Kreis, M. Kasparek, T. T. Zittel, H. D. Becker, and E. C. Jehle, "Neostigmine increases postoperative colonic motility in patients undergoing colorectal surgery," Surgery, vol. 130, no. 3, pp. 449-456, 2001.

[48] K. Nakada, A. Ikoma, T. Suzuki et al., "Amelioration of intestinal dysmotility and stasis by octreotide early after small-bowel autotransplantation in dogs," American Journal of Surgery, vol. 169, no. 3, pp. 294-299, 1995.

[49] J. J. Cullen, J. C. Eagon, and K. A. Kelly, "Gastrointestinal peptide hormones during postoperative ileus. Effect of octreotide," Digestive Diseases and Sciences, vol. 39, no. 6, pp. 1179-1184, 1994.

[50] K. Holte and H. Kehlet, "Postoperative ileus: progress towards effective management," Drugs, vol. 62, no. 18, pp. 2603-2615, 2002.

[51] M. D. Gershon, "Serotonin receptors and transportersroles in normal and abnormal gastrointestinal motility," Alimentary Pharmacology and Therapeutics, vol. 20, no. 7, pp. 3-14, 2004.

[52] F. Potet, T. Bouyssou, D. Escande, and I. Baró, "Gastrointestinal prokinetic drugs have different affinity for the human cardiac human ether-à-gogo K channel," Journal of Pharmacology and Experimental Therapeutics, vol. 299, no. 3, pp. 1007-1012, 2001.

[53] M. Tonini, F. De Ponti, A. Di Nucci, and F. Crema, "Cardiac adverse effects of gastrointestinal prokinetics," Alimentary Pharmacology and Therapeutics, vol. 13, no. 12, pp. 15851591, 1999.

[54] D. J. Roberts, H. L. Banh, and R. I. Hall, "Use of novel prokinetic agents to facilitate return of gastrointestinal motility in adult critically ill patients," Current Opinion in Critical Care, vol. 12, no. 4, pp. 295-302, 2006.

[55] J. Tack, J. Janssens, G. Vantrappen et al., "Effect of erythromycin on gastric motility in controls and in diabetic gastroparesis," Gastroenterology, vol. 103, no. 1, pp. 72-79, 1992.

[56] T. L. Peeters, "Erythromycin and other macrolides as prokinetic agents," Gastroenterology, vol. 105, no. 6, pp. 18861899, 1993.

[57] Z. Itoh, "Motilin and clinical application," Peptides, vol. 18, no. 4, pp. 593-608, 1997.

[58] M. Bonacini, S. Quiason, M. Reynolds, M. Gaddis, B. Pemberton, and O. Smith, "Effect of intravenous erythromycin on postoperative ileus," American Journal of Gastroenterology, vol. 88, no. 2, pp. 208-211, 1993. 
[59] A. J. Smith, A. Nissan, N. M. Lanouette et al., "Prokinetic effect of erythromycin after colorectal surgery: randomized, placebo-controlled, double-blind study," Diseases of the Colon and Rectum, vol. 43, no. 3, pp. 333-337, 2000.

[60] S. Jepsen, A. Klaerke, P. H. Nielsen, and O. Simonsen, "Negative effect of metoclopramide in postoperative adynamic ileus. A prospective, randomized, double blind study," British Journal of Surgery, vol. 73, no. 4, pp. 290-291, 1986.

[61] E. D. Davidson, T. Hersh, and R. A. Brinner, "The effects of metoclopramide on postoperative ileus. A randomized double-blind study," Annals of Surgery, vol. 190, no. 1, pp. 27-30, 1979.

[62] J. D. Cheape, S. D. Wexner, K. James, and D. G. Jagelman, "Does metoclopramide reduce the length of ileus after colorectal surgery? A prospective randomized trial," Diseases of the Colon and Rectum, vol. 34, no. 6, pp. 437-441, 1991.

[63] A. J. Bauer and G. E. Boeckxstaens, "Mechanisms of postoperative ileus," Neurogastroenterology and Motility, vol. 16, no. 2, pp. 54-60, 2004.

[64] R. L. Cali, P. G. Meade, M. S. Swanson, and C. Freeman, "Effect of morphine and incision length on bowel function after colectomy," Diseases of the Colon and Rectum, vol. 43, no. 2, pp. 163-168, 2000.

[65] S. Carter, "The surgical team and outcomes management: focus on postoperative ileus," Journal of Perianesthesia Nursing, vol. 21, no. 2, pp. S2-S6, 2006.

[66] H. Fukuda, D. Tsuchida, K. Koda, M. Miyazaki, T. N. Pappas, and T. Takahashi, "Impaired gastric motor activity after abdominal surgery in rats," Neurogastroenterology and Motility, vol. 17, no. 2, pp. 245-250, 2005.

[67] S. Yoshida, J. Ohta, K. Yamasaki et al., "Effect of surgical stress on endogenous morphine and cytokine levels in the plasma after laparoscopoic or open cholecystectomy," Surgical Endoscopy, vol. 14, no. 2, pp. 137-140, 2000.

[68] M. L. Austrup and G. Korean, "Analgesic agents for the postoperative period: opioids," Surgical Clinics of North America, vol. 79, no. 2, pp. 253-273, 1999.

[69] S. S. Liu, P. S. Hodgson, R. L. Carpenter, and J. R. Fricke, "ADL 8-2698, a trans-3,4-dimethyl-4-(3-hydroxyphenyl) piperidine, prevents gastrointestinal effects of intravenous morphine without affecting analgesia," Clinical Pharmacology and Therapeutics, vol. 69, no. 1, pp. 66-71, 2001.

[70] C. S. Yuan, J. F. Foss, M. O'Connor et al., "Effects of entericcoated methylnaltrexone in preventing opioid-induced delay in oral-cecal transit time," Clinical Pharmacology and Therapeutics, vol. 67, no. 4, pp. 398-404, 2000.

[71] C. S. Yuan and J. F. Foss, "Antagonism of gastrointestinal opioid effects," Regional Anesthesia and Pain Medicine, vol. 25, no. 6, pp. 639-642, 2000.

[72] C. P. Delaney, J. L. Weese, N. H. Hyman et al., "Phase III trial of alvimopan, a novel, peripherally acting, mu opioid antagonist, for postoperative ileus after major abdominal surgery," Diseases of the Colon and Rectum, vol. 48, no. 6, pp. 1114-1129, 2005.

[73] E. R. Viscusi, J. Rathmell, A. Fichera et al., "A double-blind, randomized, placebo-controlled trial of methylnaltrexone (MNTX) for post-operative bowel dysfunction in segmental colectomy patients," Anesthesiology, vol. 103: abstract A893, 2005.

[74] B. G. Wolff, F. Michelassi, T. M. Gerkin et al., "Alvimopan, a novel, peripherally acting $\mu$ opioid antagonist: results of a multicenter, randomized, double-blind, placebo-controlled, phase III trial of major abdominal surgery and postoperative ileus," Annals of Surgery, vol. 240, no. 4, pp. 728-735, 2004.
[75] E. R. Viscusi, T. J. Gan, J. B. Leslie et al., "Peripherally acting mu-opioid receptor antagonists and postoperative ileus: mechanisms of action and clinical applicability," Anesthesia and Analgesia, vol. 108, no. 6, pp. 1811-1822, 2009.

[76] M. W. Büchler, C. M. Seiler, J. R. Monson et al., "Clinical trial: alvimopan for the management of post-operative ileus after abdominal surgery: results of an international randomized, double-blind, multicentre, placebo-controlled clinical study," Alimentary Pharmacology and Therapeutics, vol. 28, no. 3, pp. 312-325, 2008.

[77] K. Ludwig, W. E. Enker, C. P. Delaney et al., "Gastrointestinal tract recovery in patients undergoing bowel resection: results of a randomized trial of alvimopan and placebo with a standardized accelerated postoperative care pathway," Archives of Surgery, vol. 143, no. 11, pp. 1098-1105, 2008.

[78] E. R. Viscusi, S. Goldstein, T. Witkowski et al., "Alvimopan, a peripherally acting mu-opioid receptor antagonist, compared with placebo in postoperative ileus after major abdominal surgery: results of a randomized, double-blind, controlled study," Surgical Endoscopy and Other Interventional Techniques, vol. 20, no. 1, pp. 64-70, 2006.

[79] E. R. Viscusi, S. Goldstein, T. Witkowski et al., "Erratum: Alvimopan, a perpherally acting mu-opioid receptor antagonist, compared with placebo in postoperative ileus after major abdominal surgery: results of a randomized, doubleblind, controlled study," Surgical Endoscopy and Other Interventional Techniques, vol. 20, no. 3, p. 537, 2006.

[80] C. S. Yuan and J. F. Foss, "Oral methylnaltrexone for opioidinduced constipation," Journal of the American Medical Association, vol. 284, no. 11, pp. 1383-1384, 2000.

[81] J. Stephenson, "Methylnaltrexone reverses opioid-induced constipation," The Lancet Oncology, vol. 3, no. 4, p. 202, 2002.

[82] "Wyeth and Progenics provide update on phase 3 clinical trial of intravenous methylnaltrexone for postoperative ileus [press release]," Collegeville, Pa and Tarrytown, NY; March 2008, http://www.progenics.com/releasedetail. cfm?releaseid $=298721$.

[83] Entereg (alvimopan) Capsules Prescribing Information, Adolor Corporation, Exton, Pa, USA, 2009.

[84] B. G. Wolff, J. L. Weese, K. A. Ludwig et al., "Postoperative ileus-related morbidity profile in patients treated with alvimopan after bowel resection," Journal of the American College of Surgeons, vol. 204, no. 4, pp. 609-616, 2007.

[85] T. J. Bell, S. A. Poston, M. D. Kraft, A. J. Senagore, C. P. Delaney, and L. Techner, "Economic analysis of alvimopan in North American phase III efficacy trials," American Journal of Health-System Pharmacy, vol. 66, no. 15, pp. 1362-1368, 2009.

[86] L. Basse, D. H. Jakobsen, P. Billesbølle, M. Werner, and H. Kehlet, "A clinical pathway to accelerate recovery after colonic resection," Annals of Surgery, vol. 232, no. 1, pp. 51-57, 2000.

[87] W. Raue, O. Haase, T. Junghans, M. Scharfenberg, J. M. Müller, and W. Schwenk, "'Fast-track" multimodal rehabilitation program improves outcome after laparoscopic sigmoidectomy: a controlled prospective evaluation," Surgical Endoscopy and Other Interventional Techniques, vol. 18, no. 10, pp. 1463-1468, 2004.

[88] C. P. Delaney, V. W. Fazio, A. J. Senagore, B. Robinson, A. L. Halverson, and F. H. Remzi, "'Fast track' postoperative management protocol for patients with high co-morbidity undergoing complex abdominal and pelvic colorectal surgery," British Journal of Surgery, vol. 88, no. 11, pp. 1533-1538, 2001. 
[89] L. Basse, J. E. Thorbøl, K. Løssl, H. Kehlet, and A. Senagore, "Colonic surgery with accelerated rehabilitation or conventional care," Diseases of the Colon and Rectum, vol. 47, no. 3, pp. 271-278, 2004.

[90] D. Hjort Jakobsen, E. Sonne, L. Basse, T. Bisgaard, and H. Kehlet, "Convalescence after colonic resection with fast-track versus conventional care," Scandinavian Journal of Surgery, vol. 93, no. 1, pp. 24-28, 2004.

[91] H. Kehlet, "Fast-track colonic surgery: status and perspectives," Recent Results in Cancer Research, vol. 165, pp. 8-13, 2005.

[92] T. Asao, H. Kuwano, J. I. Nakamura, N. Morinaga, I. Hirayama, and M. Ide, "Gum chewing enhances early recovery from postoperative ileus after laparoscopic colectomy," Journal of the American College of Surgeons, vol. 195, no. 1, pp. 30-32, 2002.

[93] E. J. Kouba, E. M. Wallen, and R. S. Pruthi, "Gum chewing stimulates bowel motility in patients undergoing radical cystectomy with urinary diversion," Urology, vol. 70, no. 6, pp. 1053-1056, 2007.

[94] R. Schuster, N. Grewal, G. C. Greaney, and K. Waxman, "Gum chewing reduces ileus after elective open sigmoid colectomy," Archives of Surgery, vol. 141, no. 2, pp. 174-176, 2006.

[95] Y. C. Yeh, E. V. Klinger, and P. Reddy, "Pharmacologic options to prevent postoperative ileus," Annals of Pharmacotherapy, vol. 43, no. 9, pp. 1474-1485, 2009.

[96] E. Matros, F. Rocha, M. Zinner et al., "Does gum chewing ameliorate postoperative ileus? Results of a prospective, randomized, placebo-controlled trial," Journal of the American College of Surgeons, vol. 202, no. 5, pp. 773-778, 2006.

[97] J. Fanning and S. Yu-Brekke, "Prospective trial of aggressive postoperative bowel stimulation following radical hysterectomy," Gynecologic Oncology, vol. 73, no. 3, pp. 412-414, 1999.

[98] K. Kraus and J. Fanning, "Prospective trial of early feeding and bowel stimulation after radical hysterectomy," American Journal of Obstetrics and Gynecology, vol. 182, no. 5, pp. 996998, 2000.

[99] L. Basse, J. L. Madsen, and H. Kehlet, "Normal gastrointestinal transit after colonic resection using epidural analgesia, enforced oral nutrition and laxative," British Journal of Surgery, vol. 88, no. 11, pp. 1498-1500, 2001.

[100] B. Person and S. D. Wexner, "The management of postoperative ileus," Current Problems in Surgery, vol. 43, no. 1, pp. 12-65, 2006

[101] M. Camilleri, "Alvimopan, a selective peripherally acting $\mu$ opioid antagonist," Neurogastroenterology and Motility, vol. 17, no. 2, pp. 157-165, 2005.

[102] N. M. H. Bulow, N. V. Barbosa, and J. B. T. Rocha, "Opioid consumption in total intravenous anesthesia is reduced with dexmedetomidine: a comparative study with remifentanil in gynecologic videolaparoscopic surgery," Journal of Clinical Anesthesia, vol. 19, no. 4, pp. 280-285, 2007.

[103] S. Chaudhri, L. Brown, I. Hassan, and A. F. Horgan, "Preoperative intensive, community-based vs. traditional stoma education: a randomized, controlled trial," Diseases of the Colon and Rectum, vol. 48, no. 3, pp. 504-509, 2005.

[104] M. I. Correia and R. G. Da Silva, "The impact of early nutrition on metabolic response and postoperative ileus," Current Opinion in Clinical Nutrition and Metabolic Care, vol. 7, no. 5, pp. 577-583, 2004.

[105] J. B. Dahl, O. Mathiesen, and H. Kehlet, "An expert opinion on postoperative pain management, with special reference to new developments," Expert Opinion on Pharmacotherapy, vol. 11, no. 15, pp. 2459-2470, 2010.

[106] H. Kehlet and D. W. Wilmore, "Multimodal strategies to improve surgical outcome," American Journal of Surgery, vol. 183, no. 6, pp. 630-641, 2002.

[107] K. Lassen, M. Soop, J. Nygren et al., "Consensus review of optimal perioperative care in colorectal surgery: enhanced recovery after surgery (ERAS) group recommendations," Archives of Surgery, vol. 144, no. 10, pp. 961-969, 2009.

[108] V. Mehta and R. M. Langford, "Acute pain management for opioid dependent patients," Anaesthesia, vol. 61, no. 3, pp. 269-276, 2006.

[109] R. Nelson, B. Tse, and S. Edwards, "Systematic review of prophylactic nasogastric decompression after abdominal operations," British Journal of Surgery, vol. 92, no. 6, pp. 673680, 2005.

[110] J. R. Pisegna and R. G. Martindale, "Acid suppression in the perioperative period," Journal of Clinical Gastroenterology, vol. 39, no. 1, pp. 10-16, 2005.

[111] J. Rømsing and S. Møiniche, "A systematic review of COX-2 inhibitors compared with traditional NSAIDs, or different COX-2 inhibitors for post-operative pain," Acta Anaesthesiologica Scandinavica, vol. 48, no. 5, pp. 525-546, 2004.

[112] P. E. Sánchez-Rodríguez, C. Fuentes-Orozco, and A. González-Ojeda, "Effect of dexamethasone on postoperative symptoms in patients undergoing elective laparoscopic cholecystectomy: randomized clinical trial," World Journal of Surgery, pp. 34895-5900, 2010.

[113] J. J. Tjandra and M. K. Y. Chan, "Systematic review on the short-term outcome of laparoscopic resection for colon and rectosigmoid cancer," Colorectal Disease, vol. 8, no. 5, pp. 375-388, 2006.

[114] U. Zingg, D. Miskovic, I. Pasternak, P. Meyer, C. T. Hamel, and U. Metzger, "Effect of bisacodyl on postoperative bowel motility in elective colorectal surgery: a prospective, randomized trial," International Journal of Colorectal Disease, vol. 23, no. 12, pp. 1175-1183, 2008.

[115] S. B. Groudine, H. A. G. Fisher, R. P. Kaufman et al., "Intravenous lidocaine speeds the return of bowel function, decreases postoperative pain, and shortens hospital stay in patients undergoing radical retropubic prostatectomy," Anesthesia and Analgesia, vol. 86, no. 2, pp. 235-239, 1998.

[116] S. S. Chang, R. G. Baumgartner, N. Wells, M. S. Cookson, and J. A. Smith Jr., "Causes of increased hospital stay after radical cystectomy in a clinical pathway setting," Journal of Urology, vol. 167, no. 1, pp. 208-211, 2002.

[117] B. W. Miedema and J. O. Johnson, "Methods for decreasing postoperative gut dysmotility," The Lancet Oncology, vol. 4, no. 6 , pp. 365-372, 2003.

[118] D. J. Schoetz, M. Bockler, M. S. Rosenblatt et al., "“Ideal” length of stay after colectomy: whose ideal?" Diseases of the Colon and Rectum, vol. 40, no. 7, pp. 806-810, 1997.

[119] E. L. Bokey, P. H. Chapuis, C. Fung et al., "Postoperative morbidity and mortality following resection of the colon and rectum for cancer," Diseases of the Colon and Rectum, vol. 38, no. 5, pp. 480-487, 1995.

[120] T. A. Pritts, M. S. Nussbaum, L. V. Flesch, E. J. Fegelman, A. A. Parikh, and J. E. Fischer, "Implementation of a clinical pathway decreases length of stay and cost for bowel resection," Annals of Surgery, vol. 230, no. 5, pp. 728-733, 1999.

[121] T. J. Gan, D. A. Lubarsky, E. M. Flood et al., "Patient preferences for acute pain treatment," British Journal of Anaesthesia, vol. 92, no. 5, pp. 681-688, 2004. 


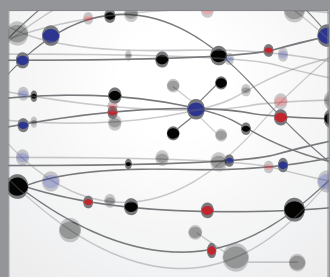

The Scientific World Journal
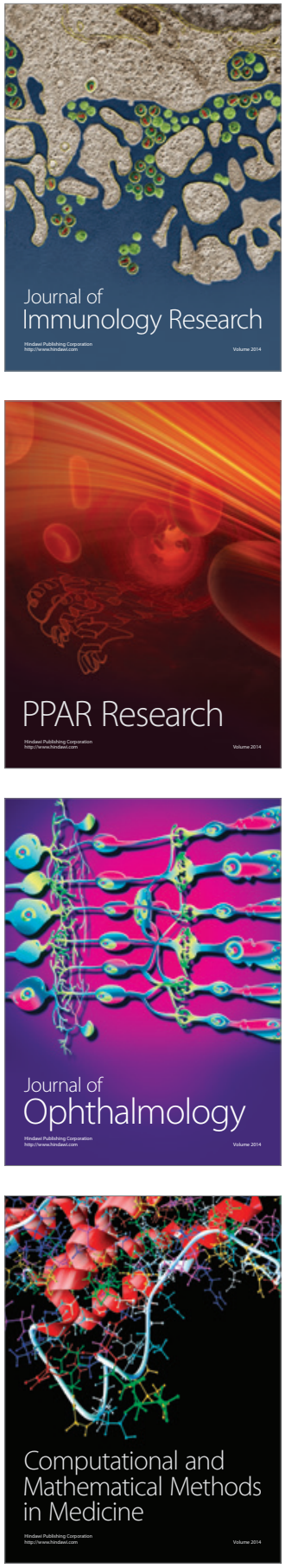

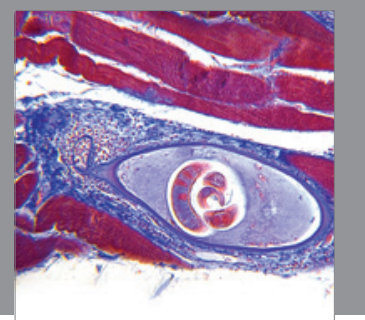

Gastroenterology

Research and Practice
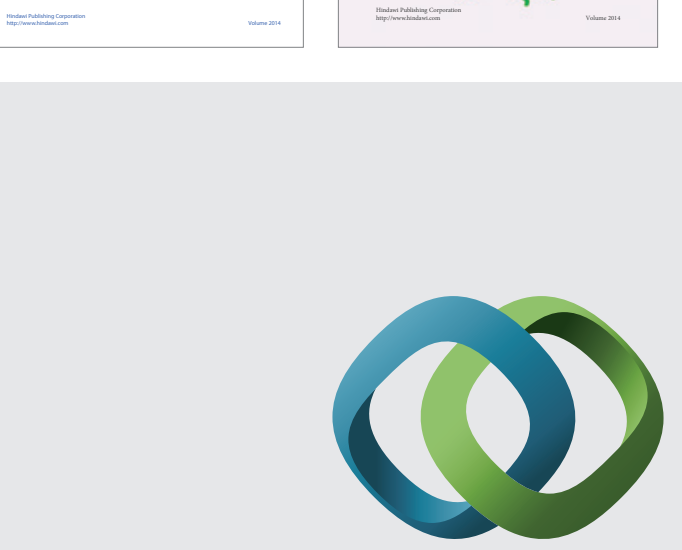

\section{Hindawi}

Submit your manuscripts at

http://www.hindawi.com
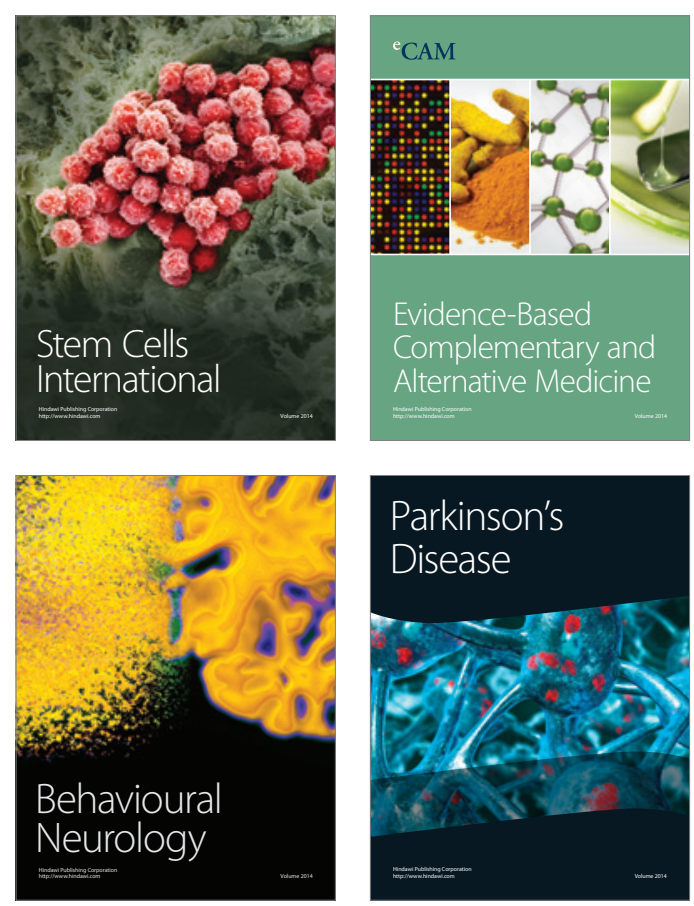

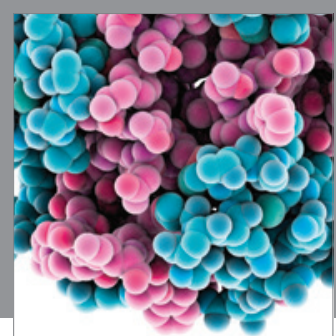

Journal of
Diabetes Research

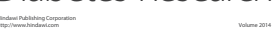

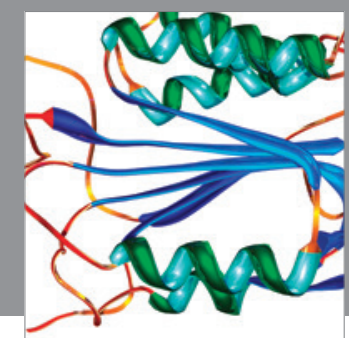

Disease Markers
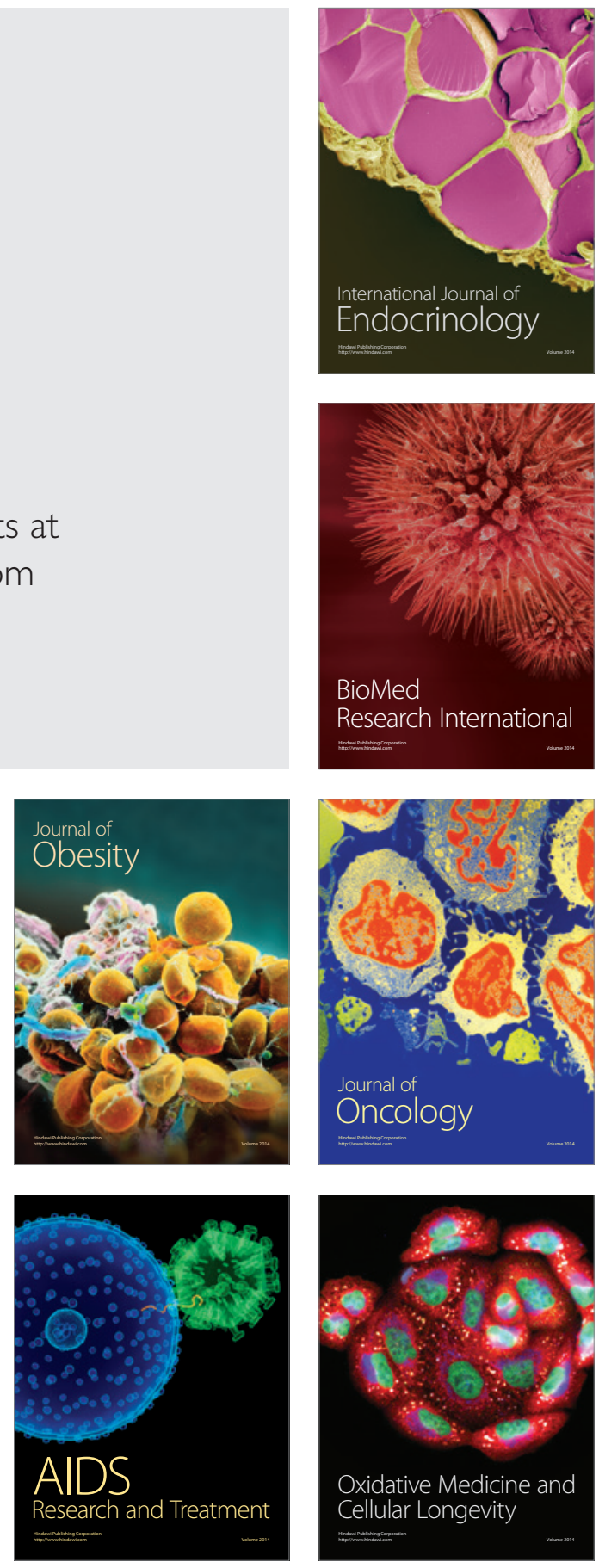